\title{
LOS CAMPAMENTOS ROMANOS DE CAMPAÑA EN EL BELLUM CANTABRICUM: ESTADO ACTUAL DE LA INVESTIGACIÓN Y NOVEDADES ARQUEOLÓGICAS
}

\author{
Víctor Vicente García \\ Universidad de Santiago de Compostela \\ victorvigarcia95@gmail.com
}

\begin{abstract}
RESUMEN: El presente trabajo tiene por objeto el estudio de la castrametación militar romana de campaña en el periodo en el que se desarrollaron las Guerras Cántabras (29-19 a. C.). Para ello, tras exponer un breve estado de la cuestión, se presentará un nuevo yacimiento que hemos identificado como un asentamiento militar romano, de acuerdo con sus particulares características morfotipológicas. Estas estructuras han sido localizadas mediante el empleo de una metodología específica que combina el uso sistemático de nuevas técnicas de teledetección y la revisión de las colecciones de ortofotografías aéreas. Con ello se obtendrán conclusiones relativas a la funcionalidad de estas estructuras y su empleo en el curso del Bellum Cantabricum.
\end{abstract}

Palabras clave: Arqueología militar romana, Guerras Cántabras, campamentos romanos, Teledetección, LiDAR.

\section{ROMAN MILITARY CAMPS OF THE CANTABRIAN WARS: STATE OF THE QUESTION AND NEW ARCHAEOLOGICAL DATA}

ABSTRACT: The aim of this paper is to study Roman military camps used in the course of the Cantabrian Wars in central north Spain (29-19 BC). After a brief current status, we will present a series of new enclosures that could be identified as Roman military sites, according to their particular morphotypological characteristics. These structures have been located through a specific methodology that combines the systematic use of new remote sensing techniques and aerial orthophotographs collections review. We will obtain 
findings about the functionality of the structures and their utilization during the Bellum Cantabricum.

Keywords: Roman military Archaeology, Cantabrian Wars, Roman military camps, Remote sensing, LiDAR.

Recibido: 24 de marzo de 2020

Aceptado: 24 de junio de 2020

\section{Introducción}

La concentración de evidencias arqueológicas relacionadas con la conquista romana del territorio ocupado por los antiguos cántabros nos empujó a elaborar un estudio cuyo objetivo principal fue precisamente la compilación, en forma de catalogo actualizado, del conjunto de yacimientos atribuibles al periodo del denominado Bellum Cantabricum (29-19 a. C.), concretamente aquellos relacionados con la poliorcética romana ${ }^{1}$. La construcción y fortificación de este tipo de recintos era ya considerada entre los tratadistas militares romanos, como el Pseudo-Hyginio, uno de los elementos más importantes del arte de la guerra. No debe extrañar, por tanto, que el estudio de los restos arqueológicos derivados de esta práctica constituya un tema de indudable interés histórico y arqueológico.

El objetivo de este artículo es la presentación de un recinto fortificado inédito, hallado recientemente en el Sistema del Escudo (Molledo y Luena, Cantabria), mediante la utilización de las más actualizadas técnicas de teledetección. Dicha presentación, precedida por una breve exposición de los avances más recientes en la historia de la investigación sobre el Bellum Cantabricum y de la metodología empleada para su identificación, se basa en el análisis exhaustivo de las características morfológicas del yacimiento, cuyas particularidades permiten sostener la hipótesis de que se trata de un establecimiento militar romano.

\section{Historia de la investigación}

El nacimiento de la arqueología militar romana en el norte peninsular como campo de estudio específico está ligado a la labor pionera del investigador alemán Adolf Schulten, quien publicó en 1943 y 1962 sus trabajos sobre las Guerras Cántabras y que, previamente, había estudiado los campamentos republicanos localizados en Numancia y Cáceres el Viejo. En la década de 1960

1. Vicente García, V., Los campamentos de campaña en el Bellum Cantabricum: Catálogo y estado de la cuestión. (Trabajo de fin de Máster). Santander 2019. 
será Antonio García y Bellido² quien retomará el testigo de los estudios sobre la transición entre el mundo indígena y el romano en la región septentrional de la península; entre sus trabajos sobre esta materia destacan las memorias de las excavaciones realizadas en los yacimientos de Herrera de Pisuerga y León.

En aquellos años no se habían estudiado aún los campamentos de campaña en el norte peninsular, si bien el descubrimiento aislado de algunos de ellos comenzó a ser ya una realidad poco después, tal como se aprecia con la publicación de los recintos de Castrocalbón (León), identificados mediante la observación de la fotografía aérea ${ }^{3}$. Estos primeros pasos en la investigación, no obstante, estaban todavía muy limitados por la información contenida en las fuentes clásicas, la procedente de los materiales epigráficos y numismáticos y los estudios toponímicos, entre otros. Así ocurre en los trabajos sobre las campañas augusteas de conquista del norte peninsular de grandes investigadores como R. Syme, G. Alföldy o Cl. Domergue, publicados entre los años setenta y ochenta del siglo pasado, en los que estas limitaciones son aún muy evidentes.

En este contexto, sería P. Le Roux ${ }^{4}$ quien marcaría un antes y un después mediante la publicación, en 1982, de una monografía de referencia para el estudio del ejército romano en Hispania, en la que puso de manifiesto el escaso desarrollo de la investigación arqueológica sobre esta cuestión. A partir de ese momento, autores como A. Morillo y E. Martín ${ }^{5}$ reconocieron el nacimiento de la arqueología militar romana como una disciplina dotada de contenido propio en el territorio peninsular ; sin embargo, para la zona que nos ocupa, el verdadero nacimiento de una arqueología de campo centrada en el estudio de las evidencias campamentales romanas no se produciría hasta bien entrada la década de 1990, de la mano de los trabajos de Eduardo Peralta y sus colaboradores ${ }^{7}$.

2. Para más información véase García y Bellido, A., "El exercitus hispanicus desde Augusto a Vespasiano". Archivo Español de Arqueología 3 (1961), pp. 114-160; "El ejército romano en Hispania". Archivo Español de Arqueología 49 (1976), pp. 59-102.

3. Loewinsohn, E., "Una calzada y dos campamentos romanos del conuentus asturum". Archivo Español de Arqueología 38 (1965), pp. 26-43.

4. Le Roux, P., L'Armée Romaine et l'organisation des provinces ibériques. D’Auguste a l'invasion de 409. Paris 1982.

5. Morillo Cerdán, Á. y Martín Hernández, E., "El ejército romano en la Península Ibérica. De la "Arqueología filológica" a la arqueología militar romana". Estudios Humanísticos, Historia 4 (2005), pp. 117-207.

6. Morillo Cerdán, Á., "Los campamentos romanos de la Meseta Norte y el Noroeste: ¿un limes sin fronteras?", C. Fernández (coord.), Los Finisterres atlánticos en la antigüedad: época prerromana y romana (coloquio internacional). 1996, pp. 77-83. Peralta Labrador, E. J., "Campamentos romanos en Cantabria". Castillos de España: publicación de la asociación española de amigos de los castillos 161-163 (2011), pp. 23-36. Costa-García, J. M., Arqueología de los asentamientos militares romanos en la Hispania Altoimperial (27 a.C.- ca 280 d.C.) (Tesis doctoral). Santiago de Compostela 2013.

7. Peralta Labrador, E. J., "Los castros Cántabros y los campamentos romanos de Toranzo y de Iguña, prospecciones y sondeos (1996-1997)", Las Guerras Cántabras. Santander 1999, pp. 203-270. 
Fue precisamente en esos años cuando comenzó a conocerse la existencia de evidencias arqueológicas claras relacionadas con la presencia militar romana en Cantabria, lo que permitió ir configurando paulatinamente un mapa de la misma desde el comienzo del Principado. Los hallazgos fueron fruto de las prospecciones practicadas en los cordales del interfluvio Pas-Besaya, realizadas por E. Peralta, F. Fernández y R. Ayllón, y la metodología de estudio que se practicó en esos momentos recurrió, de forma casi sistemática, a la observación detenida de la fotografía aérea, que resultó ser muy fructífera en la detección de estructuras campamentales.

Estos avances en la documentación del registro material se expusieron en el Primer Simposio de las Guerras Cántabras, celebrado en Santander en 1997, en el cual J. G. Echegaray, J. L. Ramírez Sádaba y E. Peralta presentaron sus descubrimientos y avances en la investigación. Algunas de las grandes evidencias arqueológicas que se mostraron entonces fueron los campamentos de El Campo de las Cercas (San Felices de Buelna y Puente Viesgo), La Muela (Merindad de Sotoscueva), Sierracastro (Pesquera), Cueto del Haya (Rionansa), La Espina del Gallego (Corvera De Toranzo y Arenas de Iguña) y el Cantón (Molledo). Su distribución sobre el terreno abría una nueva vía para estudiar los movimientos del ejercito romano en esta región ${ }^{8}$.

Poco después, la llegada del siglo XXI trajo consigo una serie de descubrimientos que permitieron definir con mayor precisión el panorama de las Guerras Cántabras. Durante la primera década, cabe destacar el descubrimiento del campamento de El Cincho (Campoo de Yuso), localizado por el investigador M. García Alonso ${ }^{9}$, así como la identificación de los dos campamentos de La Poza, en los que comenzaron a realizarse trabajos de prospección y excavación bajo la dirección de J. J. Cepeda ${ }^{10}$. A estos hallazgos pronto se sumaron nuevos descubrimientos durante las labores de prospección de E. Peralta ${ }^{11}$ en el norte de la Meseta

8. Del Olmo Martín, J., "Arqueología aérea en tres núcleos campamentales romanos de Zamora y León". Brigecio 4-5 (1995), pp. 109-118; Peralta Labrador, E. J., "Los campamentos romanos de campaña (casta aestiva): Evidencias científicas y carencias académicas". Nivel Cero 10 (2002), pp. 49-87; Peralta Labrador, E. J., "La penetración del ejército romano por el interfluvio Pas-Besaya (Cantabria)", J. Camino Mayor, E. J Peralta y J. F. Torres-Martínez (coords.), Las guerras Astur-cántabras. Gijón 2015, pp. 131-148; Aja Sánchez, J. R., Cisneros Cunchillos, M. y Ramírez Sábada, J. L., "Estado actual de la historiografía sobre la Cantabria Antigua", J. R. Aja, M. Cisneros y J. L. Ramírez (coords.), Los cántabros en la Antigüedad, la historia frente al mito. Santander 2008, pp. 33-48.

9. García Alonso, M., "El campamento de campaña de El Cincho (Campoo de Yuso, Cantabria)", J. Camino Mayor, E. J. Peralta y J. F. Torres-Martínez (coords.), Las guerras Asturcántabras. Gijón 2015, pp. 149-157.

10. Cepeda Ocampo, J. J., "Los campamentos romanos de La Poza (Cantabria)", Á. Morillo Cerdán (ed.), Arqueología militar romana en Hispania II: Producción y abastecimiento en el ámbito militar. León 2006, pp. 683-690.

11. Peralta Labrador, E. J., "La conquista romana de Campoo: arqueología de las Guerras Cántabras". Cuadernos de Campoo 36, pp. 28-42. 
Castellana, como El Alambre (Valle de Valdelucio) y los campamentos que forman el cerco de La Loma (Santibáñez de la Peña), siendo este último, sin duda, el más espectacular de los conjuntos arqueológicos del conflicto ${ }^{12}$. Por su parte, en los yacimientos de Monte Bernorio (Pomar de Valdivia) y el Castillejo se retomaron las investigaciones, paralizadas años atrás, de la mano de J. F. Torres ${ }^{13}$. También en estos años F. Didierjean ${ }^{14}$, mediante la realización de vuelos con ultraligero y avioneta, documentó por primera vez los recintos campamentales localizados en Sasamón, obteniendo la primera identificación de la morfología de los espacios y su relación con el emplazamiento de la Segisama citada por las fuentes.

Por otro lado, además de todo lo anteriormente indicado, debe señalarse también la realización de varios congresos y publicaciones colectivas en las que fueron quedando plasmados los avances en la investigación sobre la materia. Congresos como Arqueología Militar romana en Europa y Arqueología Militar Romana en Hispania, celebrados en Segovia, mediante los cuales la disciplina fue adquiriendo solidez ${ }^{15}$. Sin embargo, posiblemente el mayor avance de esta primera década fue la publicación, en el año 2007, del primer catálogo sistemático de los yacimientos militares hallados hasta la fecha en la actual Cantabria coordinado por M. L. Serna, A. Martínez y V. Fernández: Castros y Castra en Cantabria: fortificaciones desde los orígenes de la Edad del Hierro a las guerras con Roma, en el que se incluyeron también los recientemente descubiertos campamentos de La Garita (Los Corrales de Buelna y Cieza), El Castro (Valderredible) y el Robadorio (Vega de Liébana) ${ }^{16}$.

A partir de ese mismo año, investigadores como J. Á. Hierro Gárate, E. Gutiérrez Cuenca y E. Peralta ${ }^{17}$ comenzaron a realizar la revisión de ortofotografías satelitales

12. Peralta Labrador, E. J., "El asedio de La Loma (Santibáñez de la Peña, Palencia), y otros campamentos al norte de Castilla", J. Camino Mayor, E. J. Peralta y J. F. Torres-Martínez (coords.), Las guerras Astur-cántabras. Gijón 2015, pp. 91-109.

13. Torres-Martínez, J. F., "El ataque a Monte Bernorio (Villarén, Pomar de Valdivia, Palencia)", J. Camino Mayor, E. J. Peralta Labrador, y J. F. Torres-Martínez (coords.), Las guerras Astur-cántabras. Gijón 2015, pp. 111-129.

14. Didierjean, F., "Camps militaires romains et archéologie aérienne: méthodologie et données Nouvelles", en F. Cadiou, M. Á. Magallón y M. Navarro (eds.), La guerre et ses traces dans la Péninsule Ibérique à l'époque de la conquête romaine: approches méthodologiques, Actes de la Table ronde internationale. Madrid 2008, pp. 95-115.

15. Morillo Cerdán, Á. y Martín Hernández, E., "El ejército romano en la Península Ibérica. De la "Arqueología filológica" a la arqueología militar romana". Estudios Humanísticos, Historia 4 (2005), pp. 117-207; Costa-García, J. M., Arqueología de los asentamientos militares...

16. Póo Gutiérrez, M., Serna Gancedo, M. L. y Martínez Velasco, A., "Campamento (castra aestiva) de Campo de las Cercas (San Felices de Buelna y Puente Viesgo", L. Serna Gancedo, A. Martínez y V. Fernández Acebo (coords.), Castros y castra en Cantabria: fortificaciones desde los orígenes de la Edad del Hierro a las guerras con Roma: catálogo, revisión y puesta al día. Santander 2010, pp. 263-273.

17. Hierro Gárate, J. Á., Gutiérrez Cuenca, E. y Bolado del Castillo, R., "Avances en la identificación de nuevos escenarios del Bellum Cantabricum", J. Camino Mayor, E. J. Peralta 
históricas. Esta nueva metodología de estudio supuso un gran avance a la hora de localizar este tipo de yacimientos, permitiendo observar con mayor definición la superficie terrestre a cualquier usuario; así, fue convirtiéndose en un paso fundamental previo al trabajo de campo, hasta hacerse hoy en día indispensable para la disciplina. El uso de esta técnica, sumada a la realización de prospecciones en la comarca de Liébana, dio lugar al descubrimiento por parte de estos investigadores de otra serie de conjuntos campamentales como Vistrió (Pesaguero) o Castro Negro (Vega de Liébana), que fueron añadiéndose como nuevas evidencias al conjunto y permitieron precisar el mapa del desarrollo del Bellum Cantabricum.

Finalizada ya la primera década del siglo XXI, uno de los trabajos más importantes fue, sin duda, la tesis doctoral presentada por el investigador J. M. Costa ${ }^{18}$ en el año 2013. En dicha tesis, el autor realiza una clasificación y catálogo del total de recintos militares relacionados con el mundo romano descubiertos en la península ibérica hasta el momento, convirtiéndose en una obra de referencia para el estudio de esta disciplina.

Asimismo, J. M. Costa desarrolló, junto con otros investigadores, el proyecto Romanarmy.eu, cuyo objetivo principal es el estudio de la presencia militar romana en el en noroeste peninsular. Dicho proyecto, que continúa su labor en la actualidad, está siendo de suma importancia no sólo por el añadido de nuevas evidencias al registro arqueológico mediante el empleo de las nuevas técnicas de teledetección, sino también por la puesta en el punto de mira de la investigación de los escenarios indígenas afectados por el proceso de conquista ${ }^{19}$.

Otro de los proyectos más importantes que se están desarrollando a día de hoy es el dirigido por la arqueóloga E. Martín, destinado al estudio de las evidencias de las guerras con Roma en el norte de la Meseta, y gracias al cual se han podido documentar nuevas vías de avance del ejército romano en la época de las Guerras Cántabras ${ }^{20}$.

y J. F. Torres-Martínez (coords.), Las guerras Astur-cántabras. Gijón 2015, pp. 191-205; Peralta Labrador, E. J. y Camino Mayor, J., "Conclusiones sobre las Guerras Astur-Cántabras", J. Camino Mayor, E. J. Peralta y J. F. Torres-Martínez (coords.), Las guerras Astur-cántabras. Gijón 2015, pp. 345-371.

18. Costa-García, J. M., Arqueología de los asentamientos militares...

19. Costa-García, J. M., Fonte, J., Gago Mariño, M. y Blanco-Rotea, R., "Novedades sobre la presencia del ejército romano en el occidente galaico", J. Camino Mayor, E. J Peralta y J. F. Torres-Martínez (coords.), Las guerras Astur-cántabras. Gijón 2015, pp. 285-289; García-Sánchez, J., Gago Mariño, M., Costa-García, J. M. y Fernández-Götz, M., "El modelo Romanarmy. eu: patrimonio, comunicación e investigación en el pasado romano de Sasamón (Burgos)", M. Rolo (ed.), Arqueología 3-0 II. Comunicaçao, divulgaçao, e socializaçäo de arqueología. Vila Viçosa 2019, pp. 101-119; Costa-García, J. M., Fonte, J. y Gago Mariño, M., "The reassessment of the roman military presence in Galicia and northern Portugal through digital tools: Archaeological diversity and historical problems". Mediterranean Archaeology and Archaeometry vol. 19, 3 (2019), pp. 17-49.

20. Hemos de agradecer la información a Esperanza Martín, al habernos facilitado la descripción de una serie de recintos defensivos, de los que sin su colaboración no hubiésemos tenido constancia. 
No podemos terminar sin destacar la importancia que tuvo la celebración del I Encuentro Arqueológico de las Guerras Astur-Cántabras, coordinado por J. Camino, E. Peralta y J. F. Torres en el año 2014, cuyas comunicaciones fueron recogidas posteriormente en forma de publicación. Este congreso también contribuyó a la actualización del panorama al aportar novedades arqueológicas de estas guerras con Roma, además de presentar nuevos emplazamientos descubiertos tanto del territorio de Cantabria como de Asturias y Galicia.

En definitiva, en los últimos años esta nueva generación de investigadores, a la que hay que sumar los importantes avances metodológicos introducidos, están suponiendo una auténtica revolución para el conocimiento de las evidencias arqueológicas fruto del proceso de conquista romano de los territorios astur-cántabros; revolución que, sin ninguna duda, permite vislumbrar un futuro prometedor en el estudio de esta disciplina.

\section{Metodología}

A la hora de analizar el por qué del gran auge y desarrollo del estudio del Bellum Cantabricum en los últimos años, se hace imprescindible señalar la introducción, tal y como se mencionó con anterioridad, de las nuevas tecnologías en la metodología tradicional: las técnicas de teledetección. Por una parte, el acercamiento a nivel usuario de los visores web, junto con el uso de herramientas como los sistemas de información geográficos (SIG), permiten acceder a las colecciones de fotografía por satélite, lo que ha facilitado enormemente la inspección del terreno y la identificación de nuevas estructuras. Por otra parte, la irrupción de la tecnología LiDAR aérea ha resultado ser imprescindible a la hora de estudiar zonas cubiertas por la vegetación, a pesar de encontrarse en una fase muy inicial en su aplicación en el territorio peninsular ${ }^{21}$.

Para el caso que nos ocupa, ha sido precisamente el empleo de estas nuevas técnicas el que ha permitido identificar un nuevo recinto militar romano en el norte de la península. La primera labor desempeñada ha sido la revisión de los vuelos fotogramétricos históricos, disponibles en la fototeca digital del IGN22.

21. Menéndez-Blanco, A., González Álvarez, D., Álvarez Martínez, V. y Jiménez Chaparro, J. I., "Propuestas de prospección de bajo coste para la detección de campamentos romanos de campaña. El área occidental de la Cordillera Cantábrica como área de estudio". Munibe (Antropología-Arkeologia) 64 (2013), pp. 175-197; Gago Mariño, M. y Fernández Malde, A., "Un posible recinto campamental romano en O Cornado (Negreira, Galicia)". Nailos: Estudios Interdisciplinares de Arqueología 2 (2015), pp. 229-251; Costa-García, J. M. y Casal García, R. "Fotografía aérea histórica, satelital moderna y LiDAR aéreo en algunos recintos militares romanos de Castilla y León". Portugalia, Nova Serie 36 (2015), pp. 143-158.

22. http://fototeca.cnig.es/, http://ftp.itacyl.es/cartografia/03_FotogramasAereos/ 
La fotografía aérea es un recurso que se viene empleando desde el siglo XIX en arqueología, y con el transcurso del tiempo se ha convertido en un instrumento indispensable para la localización de nuevos yacimientos. Son de destacar especialmente las series A y B del Ilamado Vuelo Americano (1945/46 y 1956/57) y las de los vuelos interministeriales (1977 y 1983). Otro recurso empleado es el uso de las ortofotografías más recientes, las cuales son de especial interés a la hora de comprobar la morfología de las estructuras y apreciar diferencias de coloración en algunos cultivos; para ello, se utilizan las imágenes del Plan Nacional de Ortofotografía Aérea, en adelante PNOA, pertenecientes a los años 2004-2017; los fotogramas de Google Earth (2005-2012); Apple Maps y Bing Aerial $^{23}$.

Por oro lado, para el estudio de este yacimiento se han descargado las nubes de puntos LiDAR (Laser Imaging Detection and Ranging) de acceso libre contenidas en el servidor del Instituto Geográfico Nacional, que han permitido obtener modelos digitales del terreno (MDT y MDS) con un metro de resolución. Una vez tratados estos datos con diversas aplicaciones informáticas, se ha procedido a su estudio a través de las múltiples opciones de visualización existentes ${ }^{24}$. Ello se ha revelado como un complemento muy útil, tanto para la teledetección de nuevas estructuras como para la revisión de las ya conocidas. Se trata de un método de prospección de bajo coste que se viene desarrollando desde hace años en el noroeste peninsular, en estudios del mismo ámbito que los de este trabajo. Mediante esta técnica se han obtenido avances considerables en la identificación de los yacimientos arqueológicos a partir del reconocimiento de su morfología, y ello ha permitido, a su vez, un estudio arqueológico más preciso, concebido en ocasiones como un paso previo al trabajo sobre el terreno. Es precisamente la introducción de esta tecnología la que ofrece ya unos importantes resultados en el avance de la disciplina para el territorio peninsular ${ }^{25}$.

23. Se ha realizado a través de visores en red como: http://www.ign.es/iberpix2/visor/ y http://mapas.cantabria.es/ además de poder descargar de forma directa la cartografía: http:// centrodedescargas.cnig.es/CentroDescargas/index.jsp\#

24. Para esta labor se han utilizado las herramientas: QGIS 3.4.7 y 3.8.3; Relief Visualization Toolbox 2.0; LAStools, SAGA GIS (2.3.2) y FugroViewer 1.0.

25. Menéndez-Blanco, A., González Álvarez, D., Álvarez Martínez, V. y Jiménez Chaparro, J. I., "Propuestas de prospección de bajo coste..., pp. 175-197; Hierro Gárate, J. Á., Gutiérrez Cuenca, E. y Bolado del Castillo, R., "Avances en la identificación de nuevos escenarios..., pp. 191-205; Costa-García, J. M. y Casal García, R., “Fotografía aérea histórica..., pp. 143-158; González Álvarez, D., Álvarez Martínez, V., Menéndez-Blanco, A., Gago Mariño, M., CostaGarcía, J. M. y Fonte, J., "Seguindo os pasos do exército romano: uma proposta metodológica para a deteção de assentamentos militares romanos no Noroeste Peninsular", L. Rosas, A. C. Sousa y H. Barreira (eds.), Genius Loci: lugares e significados/places and meanings, Vol. 2. Oporto 2017, pp. 67-79. 


\section{Novedades arqueológicas: el Juncal (Molledo y Luena, Cantabria)}

El yacimiento que aquí presentamos se localiza en las estribaciones finales de la sierra del Escudo, en la misma línea de cumbres en la que se encuentran los campamentos de Cildá y Cotero de las Minas. Se sitúa en la divisoria de los municipios de Molledo y Luena, dominando visualmente al este el valle del Pas y al oeste el del Besaya, a una cota máxima de 1024 (msnm). Es superada por las cimas de Cildá (1065 m.), Cotero de las Minas (1053 m.) o Los Castrucos (1101 m.), todas ellas con restos arqueológicos relacionados con el Bellum Cantabricum y el trasiego tropas militares romanas. El agger o los parapetos defensivos son reconocibles en casi todo el recorrido, a excepción de los puntos parcialmente arrasados por una línea de alta tensión, que atraviesa las estructuras longitudinalmente en dirección (E-O), y por un camino que discurre en dirección (N-S) en su extremo oriental.

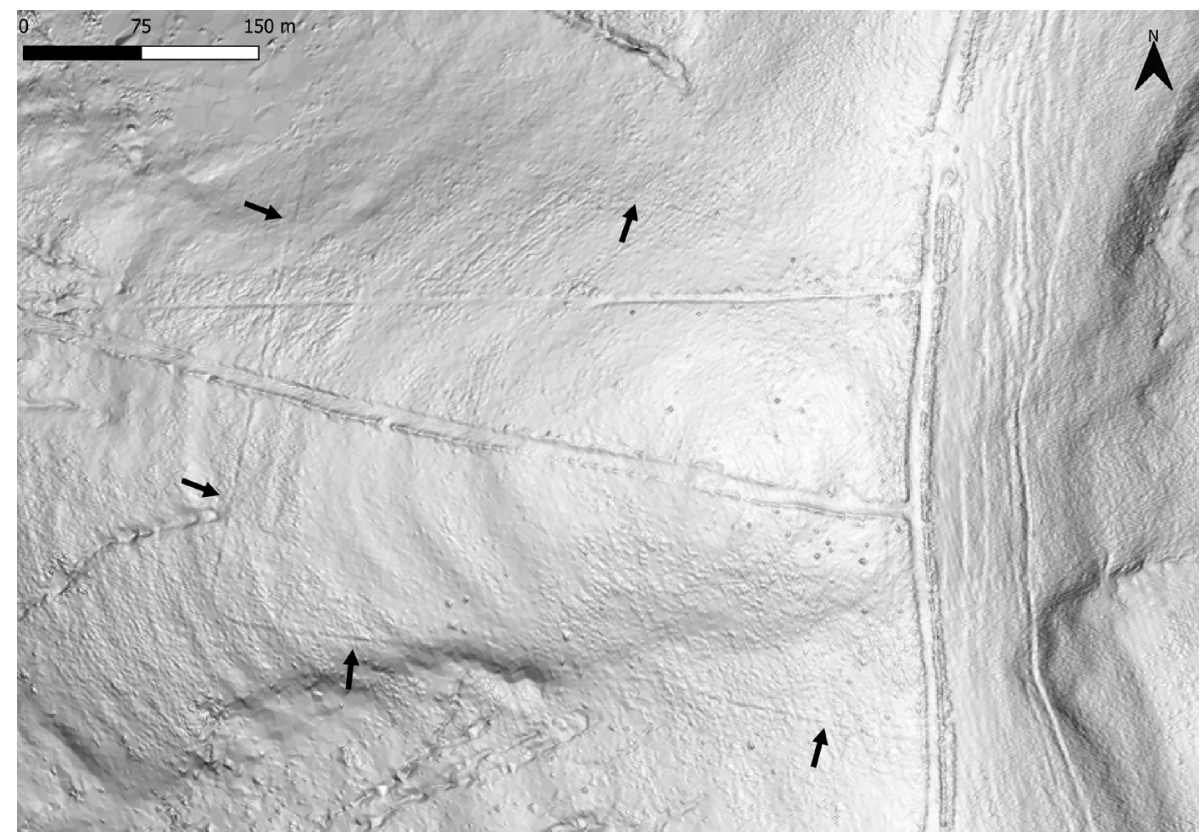

Figura 1. Recinto del Juncal (Molledo y Luena, Cantabria). Nube de puntos LiDAR procesada mediante la herramienta "Slope_8bit" (Relief Visualization Toolbox, ver. 2.0 ZRC SAZU).

El yacimiento presenta una planta de forma trapezoidal tendente a la rectangularidad con esquinas redondeadas, característica de los recintos campamentales erigidos durante las campañas realizadas en los meses de verano. Las 
estructuras que lo delimitan tienden a ser rectilíneas en sus frentes norte y oeste; las defensas del flanco meridional, por su parte, rompen esa ortogonalidad para configurarse en función de la topografía, siendo menos apreciable el parapeto defensivo en los datos LiDAR -concretamente en el segundo tercio-, donde se localiza una vaguada en el terreno. El recinto ocupa una extensión aproximada de 13,1 hectáreas ${ }^{26}$, con un eje mayor (NO-SE) que oscila entre los 425 metros en su parte menor y unos 490 metros en la zona de mayor tamaño, y el eje menor (NE-SO), que varía entre los 305 y 316 m, lo que le confiere una estimación perimetral superior a los $1152 \mathrm{~m}$. Por el momento no se puede precisar más sobre la composición de las defensas del recinto, aunque creemos que serían las habituales -vallum compuesto a base de agger y fossa-, similares a las de otros enclaves estudiados en la región, coincidentes con las descritas por el Pseudo-Higinio ${ }^{27}$.

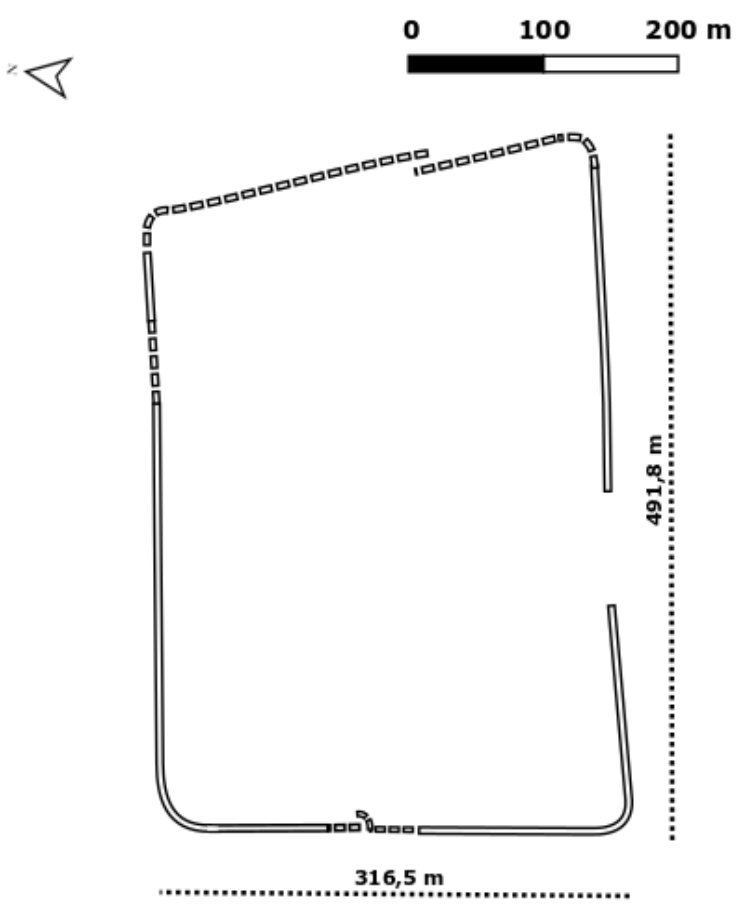

Figura 2. Recinto del Juncal (Molledo y Luena, Cantabria).

26. Tanto las medidas de sus ejes, como la extensión y su perímetro son orientativos, puesto que, al estar arrasadas las estructuras en su frente oriental, hemos tomado medidas hasta el límite interior del camino, por lo que estas no incluyen la totalidad del recinto.

27. De mun. castr. 48-53; Vegecio, I. 24-25; III. 8. 
Los accesos del campamento no han sido identificados sobre el terreno, y el procesado de los datos LiDAR sobre los que hemos trabajado puede resultar bastante impreciso para esta labor. Creemos que uno de ellos, con forma de clavicula interna, podría localizarse en el segundo tercio del parapeto occidental, al igual que otro del mismo tipo, que se encontraría en el tramo central de las defensas septentrionales; no obstante, es necesaria una actuación que confirme la morfología de los mismos. Por último, en su lado oriental se intuye lo que podría clasificarse como una entrada de lienzos paralelos, y que se articularía en torno a dos prolongaciones del agger, cuyo objetivo defensivo parece similar al conseguido con las entradas en forma de clavicula doble. Este tipo de entradas tienen su paralelo en el norte y noroeste peninsular, representado con los ejemplos de los recintos de El Llaurienzu (Asturias) y O Penedo dos Lobos (Galicia) ${ }^{28}$. Dada la acusada pendiente del flanco occidental, nos planteamos la posibilidad de que el acceso principal se localizase en el parapeto oriental, hoy en día parcialmente arrasado por el camino.

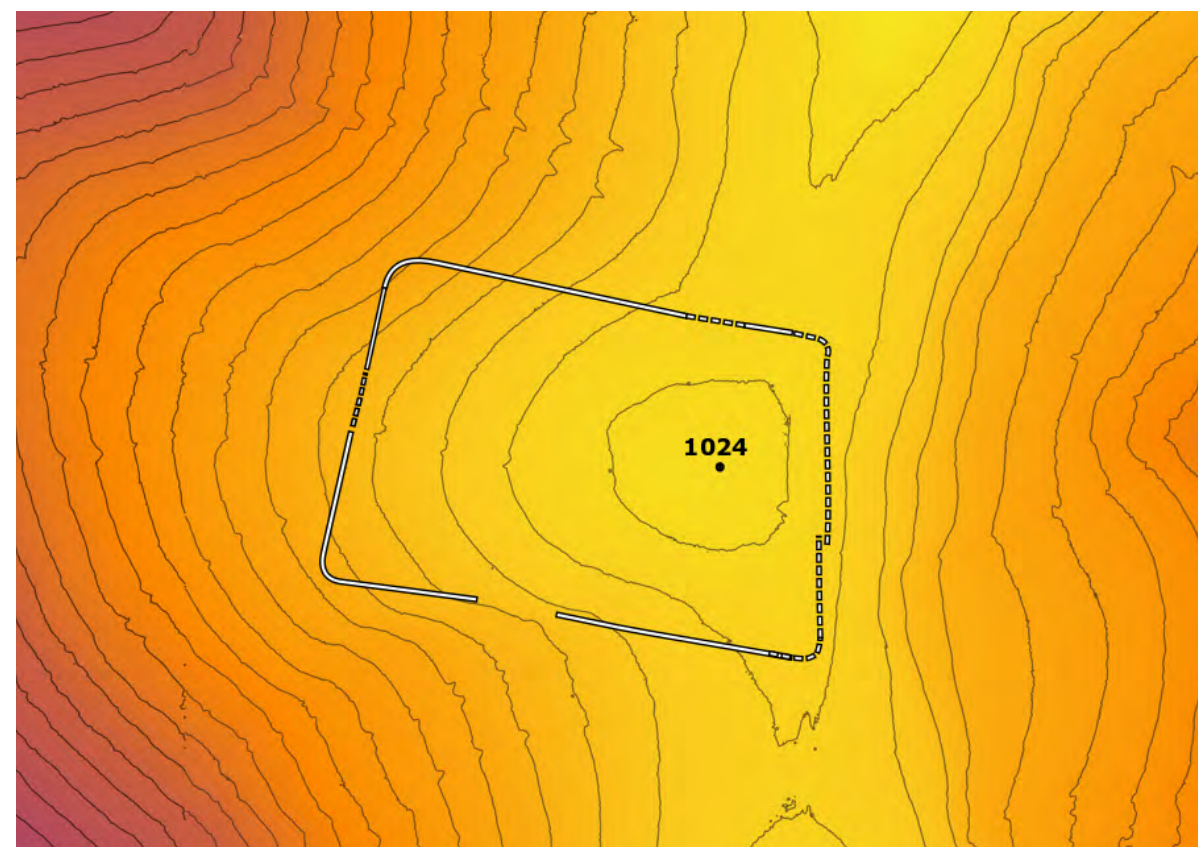

Figura 3. Planimetría del recinto Juncal, equidistancia de las curvas de nivel de $10 \mathrm{~m}$.

28. Costa-García, J. M., Fonte, J., Gago Mariño, M., Menéndez-Blanco, A. y Álvarez Martínez, V., "Hallazgos arqueológicos recientes..., pp. 39-70. 


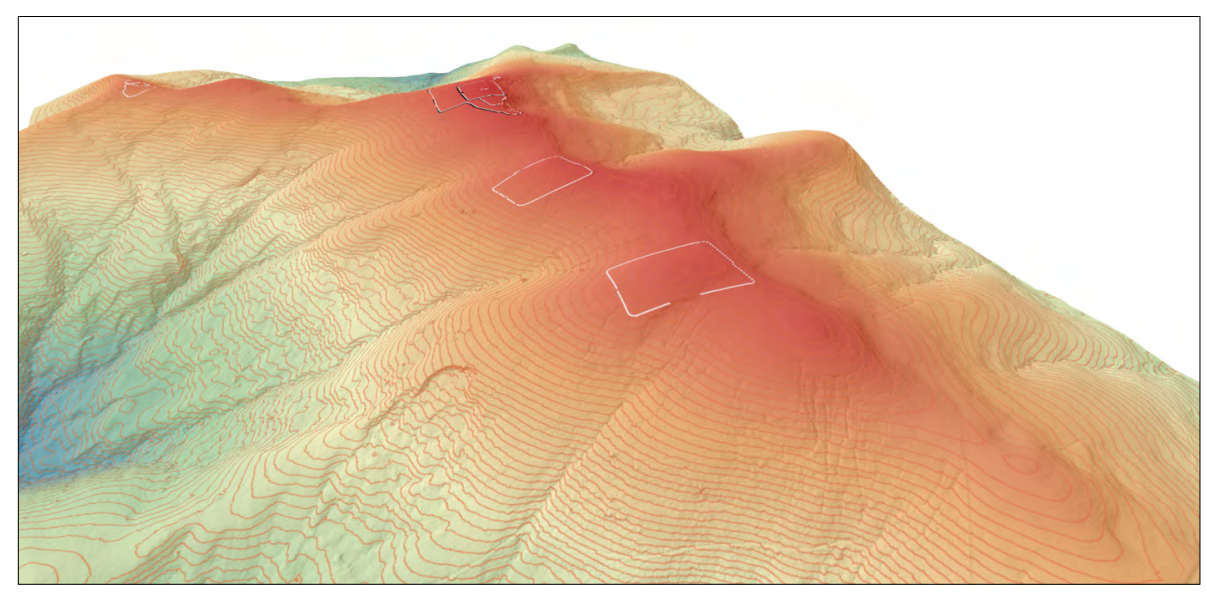

Figura 4. Vista isométrica del yacimiento sobre el modelo 3D realizado a partir del MDT (Visualización: RVT Slope).

\section{Conclusiones}

El yacimiento denominado El Juncal se configura como una gran estructura rectangular, tendente a la forma de naipe, constituido a base de agger y fossa. Estas características, sumadas a sus dimensiones y ortogonalidad, nos han llevado identificarlo con un recinto campamental militar romano, dadas las grandes similitudes que presenta con otros ya ampliamente conocidos y estudiados en la misma zona ${ }^{29}$.

A nuestro parecer, el recinto de El Juncal podría encajar con el patrón de asentamiento tipo C1 -castra in monte- de la clasificación propuesta por J. M. $\operatorname{Costa}^{30}$, es decir, enclaves localizados que siguen la línea del cordal montañoso, pero no necesariamente se sitúan en el punto más elevado.

En otra instancia, este recinto debe ser estudiado dentro de un contexto espacial y arqueológico más amplio, dada su cercanía a muchos otros yacimientos militares romanos, entre ellos Cildá, Los Castrucos o Cotero de las Minas. De hecho, la elevada cantidad de evidencias castramentales romanas existente en la línea de cumbres que discurre por las cimas del Escudo, nos Ileva a pensar en el continuo trasiego de tropas a través de estos caminos. Tanto en fases de la

29. Peralta Labrador, E. J., "El asedio romano del castro de La Espina del Gallego (Cantabria) y el problema de Aracelium". Complutum 10 (1999), pp. 195-212.

30. Costa-García, J. M. Arqueología de los asentamientos militares.. 
guerra como en tiempos posteriores, esta vía debió ser una de las principales líneas de avance en su ruta hacia o desde la costa, puesto que sus pendientes no son muy acusadas, lo que sería ventajoso para el tránsito de carros que abastecían a los contingentes militares.

Por otro lado, todo este conjunto de yacimientos también lleva al planteamiento de nuevas preguntas sobre la posible intervención de los mismos en el escenario de la toma de La Espina del Gallego, así como sobre el patrón de asentamiento romano a través de los cordales en los sistemas montañosos.

A pesar de todo lo anteriormente indicado, aún queda mucho trabajo por hacer desde el punto de vista investigador. La acumulación de nuevos datos arqueológicos abre nuevas perspectivas de estudio para esta cuestión, pero gran cantidad de estos yacimientos apenas han sido analizados en detalle mediante técnicas de prospección convencionales, es decir, intensivas, magnéticas o sondeos arqueológicos, trabajos que sin lugar a dudas contribuirían a establecer una correcta caracterización crono-funcional de los mismos.

Antes de finalizar, es relevante señalar que este tipo de yacimientos, cuyas estructuras se caracterizan por su gran envergadura y por su escasa solidez, son elementos generalmente sensibles ante la acción de diferentes procesos naturales o humanos, lo que podría acelerar su deterioro y desaparición. Así ocurre en el caso de El Juncal, afectado en su totalidad por los bancales realizados para la reforestación, lo que dificulta su adecuado reconocimiento sobre el terreno; esta situación pone de manifiesto la necesidad de garantizar su buena conservación, imprescindible a la hora de realizar futuras investigaciones.

\section{Bibliografía}

Aja Sánchez, J. R., Cisneros Cunchillos, M. y Ramírez Sábada, J. L., "Estado actual de la historiografía sobre la Cantabria Antigua", J. R. Aja; M. Cisneros y J. L. Ramírez (coords.), Los cántabros en la Antigüedad, la historia frente al mito. Santander 2008, pp. 33-48.

Aja Sánchez, J. R., Cisneros Cunchillos, M., Morillo Cerdán, Á. y Ramírez Sábada, J. L., "Cantabria bajo el dominio de Roma: La organización del territorio", J. R. Aja; M. Cisneros y J. L. Ramírez (coords.), Los cántabros en la Antigüedad, la historia frente al mito. Santander 2008, pp. 133-155.

Bolado del Castillo, R., Ocejo Herrero, Á., Gutiérrez Cuenca, E., Hierro Gárate, J. Á. y Cabria Gutiérrez, J. C., Cántabros: Origen de un pueblo. Santander 2012.

Cepeda Ocampo, J. J., "Los campamentos romanos de La Poza (Cantabria)”, Á. Morillo Cerdán (ed.), Arqueología militar romana en Hispania II: Producción y abastecimiento en el ámbito militar. León 2006, pp. 683-690. 
Costa-García, J. M., Arqueología de los asentamientos militares romanos en la Hispania Altoimperial (27 a.C.- ca 280 d.C.) (Tesis doctoral). Santiago de Compostela 2013.

Costa-García, J. M., Fonte, J., Gago Mariño, M. y Blanco-Rotea, R., "Novedades sobre la presencia del ejército romano en el occidente galaico", J. Camino Mayor, E. J Peralta y J. F. Torres-Martínez (coords.), Las guerras Astur-cántabras. Gijón 2015, pp. 285-289.

Costa-García, J. M., Menéndez Blanco, A., González Álvarez, D., Gago, M., Blanco-Rotea, R. y Álvarez Martínez, V., "Roman military settlements in the Northwest of the Iberian Peninsula. The contribution of historical and modern Aerial photography, satellite imagery and airborne LiDAR". AARGnews 52, pp. 43-51.

Costa-García, J. M., Fonte, J., Gago Mariño, M., Menéndez Blanco, A. y Álvarez Martínez, V., "Hallazgos arqueológicos recientes para el estudio de la presencia militar romana en el oriente gallego". Gallaecia 35 (2017), pp. 39-70.

Costa-García, J. M., Fonte, J. y Gago Mariño, M., "The reassessment of the roman military presence in Galicia and northern Portugal through digital tools: Archaeological diversity and historical problems". Mediterranean Archaeology and Archaeometry 19 (3) (2019), pp. 17-49. https://doi.org/10.5281/ zenodo.3457524

Del Olmo Martín, J., "Arqueología aérea en tres núcleos campamentales romanos de Zamora y León". Brigecio 4-5 (1995), pp. 109-118.

Didierjean, F., "Camps militaires romains et archéologie aérienne: méthodologie et données Nouvelles", F. Cadiou, M. Á. Magallón y M. Navarro (eds.), La guerre et ses traces dans la Péninsule Ibérique à lépoque de la conquête romaine: approches méthodologiques, Actes de la Table ronde internationale. Madrid 2008, pp. 95-115.

Eck, W., The Age of Augustus. New Jersey 2007.

Fernández Vega, P. Á. y Bolado del Castillo, R., "Castro y campamento de Santa Marina (Monte Ornedo, Valdeolea)", M. L. Serna Gancedo, A. Martínez y V. Fernández Acebo (coords.), Castros y castra en Cantabria: fortificaciones desde los orígenes de la Edad del Hierro a las guerras con Roma: catálogo, revisión y puesta al día. Santander 2010, pp. 379-386.

Gago Mariño, M. y Fernández Malde, A., "Un posible recinto campamental romano en O Cornado (Negreira, Galicia)". Nailos: Estudios Interdisciplinares de Arqueología 2 (2015), pp. 229-251.

García Alonso, M., "El campamento de campaña de El Cincho (Campoo de Yuso, Cantabria)", J. Camino Mayor, E. J. Peralta y J. F. Torres-Martínez (coords.), Las guerras Astur-cántabras. Gijón 2015, pp. 149-157.

García Alonso, M. y Cortés Montes, C., "Las puertas del campamento romano de EI Cincho (La Población, Campoo de Yuso)", Sautuola XXI. Santander 2019, pp. 47-68. 
García-Sánchez, J., Gago Mariño, M., Costa-García, J. M. y Fernández-Götz, M., "El modelo Romanarmy.eu: patrimonio, comunicación e investigación en el pasado romano de Sasamón (Burgos)", M. Rolo (ed.), Arqueología 3-0 II. Comunicaçao, divulgaçao, e socializaçäo de arqueología. Vila Viçosa 2019, pp. 101-119.

García y Bellido, A., "El exercitus hispanicus desde Augusto a Vespasiano". Archivo Español de Arqueología 3 (1961), pp. 114-160.

García y Bellido, A., "El ejército romano en Hispania". Archivo Español de Arqueología 49 (1976), pp. 59-102.

Gilliver, C. M., The Roman Art of War. Stroud 1999.

González Álvarez, D., Álvarez Martínez, V., Menéndez-Blanco, A., Gago Mariño, M., Costa-García, J. M. y Fonte, J., "Seguindo os pasos do exército romano: uma proposta metodológica para a deteção de ssentamentos militares romanos no Noroeste Peninsular", L. Rosas, A. C. Sousa y H. Barreira (eds.), Genius Loci: lugares e significados/places and meanings, Vol. 2. Oporto 2017, pp. 67-79.

Hierro Gárate, J. Á., Gutiérrez Cuenca, E. y Bolado del Castillo, R., "Avances en la identificación de nuevos escenarios del Bellum Cantabricum", J. Camino Mayor, E. J. Peralta y J. F. Torres-Martínez (coords.), Las guerras Astur-cántabras. Gijón 2015, pp. 191-205.

Le Roux, P., L’Armée Romaine et l'organisation des provinces ibériques. D’Auguste a l'invasion de 409. Paris 1982.

Loewinsohn, E., "Una calzada y dos campamentos romanos del conuentus asturum". Archivo Español de Arqueología 38 (1965), pp. 26-43.

Menéndez-Blanco, A., González Álvarez, D., Álvarez Martínez, V. y Jiménez Chaparro, J. I., "Propuestas de prospección de bajo coste para la detección de campamentos romanos de campaña. El área occidental de la Cordillera Cantábrica como área de estudio". Munibe (Antropología-Arkeologia) 64 (2013), pp. 175-197.

Morillo Cerdán, Á., "Los campamentos romanos de la Meseta Norte y el Noroeste: ¿un limes sin fronteras?", C. Fernández (coord.), Los Finisterres atlánticos en la antigüedad: época prerromana y romana (coloquio internacional). 1996, pp. 77-83.

Morillo Cerdán, Á. y Martín Hernández, E., "El ejército romano en la Península Ibérica. De la 'Arqueología filológica' a la arqueología militar romana". Estudios Humanísticos, Historia 4 (2005), pp. 117-207.

Peralta Labrador, E. J., "Los castros cántabros y los campamentos romanos de Toranzo y de Iguña, prospecciones y sondeos (1996-1997)", Las Guerras Cántabras. Santander 1999, pp. 203-270.

Peralta Labrador, E. J., "El asedio romano del castro de La Espina del Gallego (Cantabria) y el problema de Aracelium". Complutum 10 (1999), pp. 195-212. 
Peralta Labrador, E. J., "Los campamentos romanos de campaña (casta aestiva): Evidencias científicas y carencias académicas". Nivel Cero 10 (2002), pp. 49-87.

Peralta Labrador, E. J., "La conquista romana de Campoo: arqueología de las Guerras Cántabras". Cuadernos de Campoo 36, pp. 28-42.

Peralta Labrador, E. J., "Campamentos romanos en Cantabria". Castillos de España: publicación de la asociación española de amigos de los castillos 161-163 (2011), pp. 23-36.

Peralta Labrador, E. J., "La penetración del ejército romano por el interfluvio Pas-Besaya (Cantabria)", J. Camino Mayor, E. J. Peralta y J. F. Torres-Martínez (coords.), Las guerras Astur-cántabras. Gijón 2015, pp. 131-148.

Peralta Labrador, E. J., "El asedio de La Loma (Santibáñez de la Peña, Palencia), y otros campamentos al norte de Castilla", J. Camino Mayor, E. J. Peralta y J. F. Torres-Martínez (coords.), Las guerras Astur-cántabras. Gijón 2015, pp. 91-109.

Peralta Labrador, E. J. y Camino Mayor, J., "Conclusiones sobre las Guerras Astur-Cántabras", J. Camino Mayor, E. J. Peralta y J. F. Torres-Martínez (coords.), Las guerras Astur-cántabras. Gijón 2015, pp. 345-371.

Polibios, Historias: Libros V-XV, M. Balasch (trad. y n.), Biblioteca clásica de Gredos, Vol. 43. Madrid 1985.

Póo Gutiérrez, M., Serna Gancedo, M. L. y Martínez Velasco, A., "Campamento (castra aestiva) de Campo de las Cercas (San Felices de Buelna y Puente Viesgo", L. Serna Gancedo, A. Martínez y V. Fernández Acebo (coords.), Castros y castra en Cantabria: fortificaciones desde los orígenes de la Edad del Hierro a las guerras con Roma: catálogo, revisión y puesta al día. Santander 2010, pp. 263-273.

Pseudo-Higinius, "The munitionibus castrorum: Text and Translation". C. M. GiIliver (ed.), 1993.

Reddé, M., "Titulum et clavicula. À propos des fouilles rècentes d’Alesia". Revue Archéologique de l'Est et du Cen-tre-Est 46 (1995), pp. 349-356.

Richardson, A., Theoretical Aspects of Roman Camp Fort Design. Oxford 2004.

Torres-Martínez, J. F., "El ataque a Monte Bernorio (Villarén, Pomar de Valdivia, Palencia)", J. Camino Mayor, E. J. Peralta Labrador, y J. F. Torres-Martínez (coords.), Las guerras Astur-cántabras. Gijón 2015, pp. 111-129.

Vegetius Renatus, F., Instituciones militares. Madrid 1988.

Vicente García, V., Los campamentos de campaña en el Bellum Cantabricum: Catálogo y estado de la cuestión. (Trabajo de fin de Máster). Santander 2019. 